\title{
Modeling for Micro Traffic Flow with the Consideration of Lateral Vehicle's Influence
}

\author{
Da-wei Liu, ${ }^{1,2}$ Zhong-ke Shi ${ }^{1},{ }^{1}$ and Wen-Huan $\mathrm{Ai}^{3}$ \\ ${ }^{1}$ School of Automation, Northwestern Polytechnical University, Xi'an 710072, Shaanxi, China \\ ${ }^{2}$ College of Electrical Engineering, Lanzhou Institute of Technology, Lanzhou 730050, Gansu, China \\ ${ }^{3}$ College of Computer Science \& Engineering, Northwest Normal University, Lanzhou 730050, Gansu, China
}

Correspondence should be addressed to Zhong-ke Shi; shizknwpu@163.com

Received 27 May 2019; Revised 18 August 2019; Accepted 16 September 2019; Published 19 September 2020

Guest Editor: Hao Yu

Copyright ( 92020 Da-wei Liu et al. This is an open access article distributed under the Creative Commons Attribution License, which permits unrestricted use, distribution, and reproduction in any medium, provided the original work is properly cited.

In order to make the car-following model describe the driving behavior of vehicle on urban road more accurately, existing carfollowing models are simulated using measured traffic data. According to the analysis of the simulation result, two new improved car-following models based on the optimal velocity model (OVM) are proposed in this paper. The lateral vehicle's influence is introduced as the influence factor of driving behavior. By using of linear stability analysis, stability conditions of improved carfollowing models are obtained. Nonlinear analysis is carried out to investigate the traffic performances near the critical point. The result of numerical simulation indicates that stability of traffic flow is under the influence from lateral vehicle; the lesser the influence, the greater the stability. New cooperative car-following models are verified by the traffic flow data collected in Xi'an city. It is shown that compared with the optimal velocity model, the simulation result of the second cooperative model, respectively, gets $62.89 \%$ unbiased variance reduction, $66.39 \%$ maximum absolute error reduction, and $33.4 \%$ minimum absolute error reduction. Therefore, the second cooperative model is more suitable to describe the vehicle's actual behavior in car-following state.

\section{Introduction}

Car-following theory is one of the most important parts of modern traffic theory, which describes the dynamic behaviors of one vehicle following the other, and usually used in the study of microscopic traffic flow. The car-following theory has developed rapidly in recent decades, and an increasing number of models have been put forward, which include the early nonlinear models proposed by Pipes [1], Newell [2], the recent classic model presented by Bando et al. [3], Helbing and Tilch [4] and Jiang et al. [5], and some others in the literature [6-24]. Bando et al. [3] proposed a remarkable car-following model called the optimal velocity model (OVM) because it solves the problem of describing the motion of successive vehicles. By considering both the negative and the positive velocity differences, Jiang et al. [5] developed a full velocity difference model (FVDM). Some scholars considered more headway information of vehicles ahead and proposed some extended optimal velocity models.
Based on OVM, Wagner [6] put forward a new model called the looking forward model because it contains the location information of multiple vehicles ahead. Hasebe et al. [7] further expanded the OVM by introducing the headway information of $\mathrm{K}$ vehicles ahead and proved that the new model can improve the stability of traffic flow more than the OVM from the perspective of the linear response. Chen et al. [8] extended the single lane feedback model by introducing improved lane-changing rules and analyzed the influence of feedback signal on the stability of traffic flow. Li et al. [9] proposed a heterogeneous car-following model with lowand high-sensitivity vehicles by constructing the motion equation of individual vehicle. In the proposed model, all driver-vehicle units are described by the same model using two different parameter values of sensitivity. Peng et al. [10] explored the effect of the V2V communication and proposed a delayed-feedback control method for the car-following model. In our prior work [11], we developed an extended full velocity difference model by taking the short-term driving 
memory into account. We found that short-term driving memory can significantly affect the driver's driving behavior.

Most of the above models are based on such basic assumptions that the driver always keeps following the leading vehicle and responds immediately to the change of the driving state of the leading vehicle. In recent years, scholars found that the driver is also influenced by the driving state of the lateral adjacent vehicles. Tang et al. $[12,13]$ put forward a new two-lane car-following model by taking the influence of adjacent-ahead vehicle on the car-following behavior into account. Ge et al. [14] believed that vehicles will be subject to the friction interference from the vehicle of neighbor lane, and the friction interference is related to the lateral distance between the vehicle and its closest-ahead vehicle in the neighbor lane. Based on this consideration, they investigated an extended two-lane traffic flow with lane-changing behaviors and derived the stability condition by using the control method.

With the consideration of influence of lateral vehicle, an improved car-following model based on the OVM is proposed in this paper. It is common to see in real traffic that for some special reasons, for example, weather condition, health conditions, driving technology, and personal habits, the driver often does not keep up with the leading vehicle but drives at a velocity similar to that of lateral vehicles to form a stable vehicle group. Therefore, the lateral vehicles are in role of auxiliary reference. This phenomenon is an incomplete car-following behavior. In view of the above discussions, by using the general force framework, the influence of both the leading vehicle and the lateral adjacent vehicle is used as stimulus in the new proposed model. This paper is organized as follows. In Section 2, the driving phenomenon is described. In Section 3, an improved car-following model based on the OVM is developed by taking into account the lateral effect. Linear stability analysis is carried out in Section 4 , and the stability condition of the improved model is obtained. In Section 5, the MKDV equation near the critical point is derived by using nonlinear analysis. In Section 6, a series of numerical simulations are proposed to confirm the theoretical results. Conclusions are given in Section 7.

\section{Description and Analysis of Driving Phenomenon}

2.1. Description of Driving Phenomenon. In actual traffic, one can often observe a phenomenon that although the headway between vehicle and its leader vehicle is larger, the driver still keeps a similar velocity to the surrounding vehicles and does not accelerate to shorten the distance from the leader vehicle. For example, the two investigated vehicles in Figure 1 are, respectively, marked as car 1 and car 2 . Obviously, the driving state of car 2 is in accordance with the driving rules that can be described by the classic car-following model. However, despite a greater distance from the leader vehicle, car 1 still keeps the same velocity as its adjacent car on the right side. This phenomenon cannot be described by carfollowing models mentioned above because car 1 did not keep up with its leading car according to the rules describing by those car-following models.

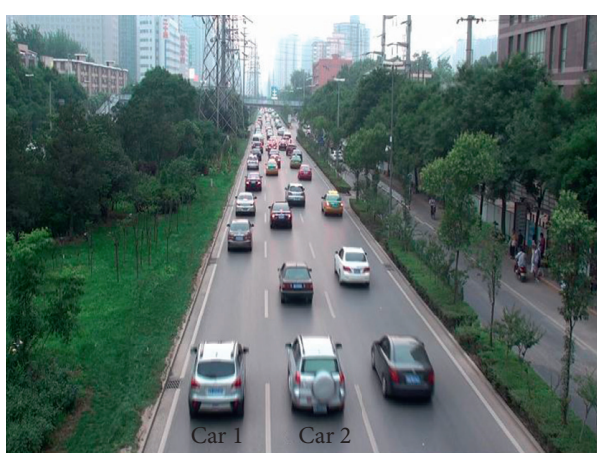

Figure 1: Real traffic.

2.2. Analysis of Driving Phenomenon. Figure 1 is intercepted from video captured by a camera. An overpass with 7.6 meter high in the South Second Ring Road of Xi'an City is selected for the field data collection. The location of the camera is identified as coordinate origin, and the distance between the coordinate origin and the lower edge of Figure 1 is 17.5 meters. For ensuring the measurement accuracy, measurement range is set from 17.5 meters to 89.5 meters because the larger shooting distance will reduce the measurement accuracy. The video is intercepted a set of images by frame/ 0.2 seconds. With the method of geometric transformation, one-to-one relationship can be established between image coordinates and vehicle's actual position.

Data of the vehicles in Figure 1 can be seen in Table 1. Since the data obtained from images are discrete data, average velocity of vehicle in every image can be calculated. Velocity data are fitted by polynomial, and the function curves of velocity-time are obtained in Figure 2.

Figures 2(a) and 2(b) are, respectively, the headway-time curves and velocity-time curves of vehicles. From Figure 2(a), the headway of car 1 is larger than that of car 2. Most of the time, the headway of car 1 is larger than 15 meters, while the headway of car 2 is smaller than 5 meters. From Figure 2(b), it can be found that the two investigated vehicles always have similar velocity and that the trends of velocity changes are roughly the same.

Two classical car-following models, optimal velocity model (OVM) and full velocity difference model (FVDM), are used to simulate the driving state of car 1 in Figure 1:

$$
\begin{aligned}
& \frac{\mathrm{d}^{2} x_{j}(t)}{\mathrm{d} t^{2}}=a\left[V\left(\Delta x_{j}(t)\right)-v_{j}(t)\right], \\
& \frac{\mathrm{d}^{2} x_{j}(t)}{\mathrm{d} t^{2}}=a\left[V\left(\Delta x_{j}(t)\right)-v_{j}(t)\right]+\lambda \Delta v_{j}(t) .
\end{aligned}
$$

Equations (1) and (2) are, respectively, the expressions of OVM and FVDM, where $a$ denotes sensitivity; $x_{j}(t)$ and $v_{j}(t)$ are, respectively, the position and velocity of the vehicle $j$ at time $t ; \Delta x_{j}(t)$ and $\Delta v_{j}(t)$ are the headway and the velocity difference between the preceding vehicle and the following vehicle, respectively; $V\left(\Delta x_{j}(t)\right)$ presents the optimal velocity function; and $\lambda$ denotes the sensitivity of velocity difference $\Delta v_{j}(t)$. 
Table 1: Data of the vehicle in Figure 1.

\begin{tabular}{|c|c|c|c|c|c|c|c|c|c|c|}
\hline \multirow[b]{2}{*}{$\begin{array}{l}\text { Time } \\
\text { (s) }\end{array}$} & \multicolumn{5}{|c|}{ The left lane } & \multicolumn{5}{|c|}{ The right lane } \\
\hline & $\begin{array}{l}\text { Position of } \\
\text { leading car }\end{array}$ & $\begin{array}{c}\text { Position of } \\
\text { following } \\
\text { car }\end{array}$ & Headway & $\begin{array}{l}\text { Velocity of } \\
\text { leading car }\end{array}$ & $\begin{array}{c}\text { Velocity of } \\
\text { following } \\
\text { car }\end{array}$ & $\begin{array}{l}\text { Position of } \\
\text { leading car }\end{array}$ & $\begin{array}{c}\text { Position of } \\
\text { following } \\
\text { car }\end{array}$ & Headway & $\begin{array}{l}\text { Velocity of } \\
\text { leading car }\end{array}$ & $\begin{array}{c}\text { Velocity of } \\
\text { following } \\
\text { car }\end{array}$ \\
\hline 0 & 37.09 & 17.75 & 19.34 & 11.18 & 9.36 & 22.55 & 17.44 & 5.11 & 10.36 & 10.67 \\
\hline 0.2 & 39.55 & 19.86 & 19.69 & 10.18 & 9.10 & 24.91 & 19.89 & 5.02 & 9.92 & 10.41 \\
\hline 0.4 & 41.32 & 21.61 & 19.71 & 9.48 & 8.91 & 26.79 & 21.88 & 4.91 & 9.60 & 10.22 \\
\hline 0.6 & 42.78 & 23.05 & 19.73 & 9.02 & 8.79 & 28.21 & 23.54 & 4.67 & 9.36 & 10.08 \\
\hline 0.8 & 45 & 25.11 & 19.89 & 8.74 & 8.72 & 30.57 & 25.84 & 4.73 & 9.19 & 9.99 \\
\hline 1.0 & 46.54 & 26.51 & 20.03 & 8.59 & 8.69 & 32.11 & 27.48 & 4.63 & 9.07 & 9.92 \\
\hline 1.2 & 48.37 & 28.58 & 19.79 & 8.52 & 8.70 & 34.18 & 29.9 & 4.28 & 8.97 & 9.86 \\
\hline 1.4 & 50.14 & 30.41 & 19.73 & 8.49 & 8.74 & 35.85 & 31.91 & 3.94 & 8.89 & 9.80 \\
\hline 1.6 & 51.6 & 31.77 & 19.83 & 8.47 & 8.79 & 37.33 & 33.33 & 4 & 8.80 & 9.73 \\
\hline 1.8 & 53.83 & 33.97 & 19.86 & 8.43 & 8.85 & 39.42 & 35.76 & 3.66 & 8.71 & 9.65 \\
\hline 2.0 & 55.02 & 35.67 & 19.35 & 8.35 & 8.92 & 41.18 & 37.86 & 3.32 & 8.60 & 9.54 \\
\hline 2.2 & 56.51 & 37.07 & 19.44 & 8.21 & 8.98 & 42.63 & 39.23 & 3.4 & 8.46 & 9.40 \\
\hline 2.4 & 58.62 & 39.23 & 19.39 & 8.01 & 9.03 & 44.51 & 41.29 & 3.22 & 8.31 & 9.23 \\
\hline 2.6 & 59.73 & 40.69 & 19.04 & 7.75 & 9.06 & 46.01 & 42.92 & 3.09 & 8.13 & 9.03 \\
\hline 2.8 & 61.48 & 42.92 & 18.56 & 7.43 & 9.06 & 47.99 & 44.97 & 3.02 & 7.93 & 8.81 \\
\hline 3.0 & 63.01 & 44.69 & 18.32 & 7.06 & 9.04 & 49.54 & 46.76 & 2.78 & 7.72 & 8.55 \\
\hline 3.2 & 63.96 & 46.15 & 17.81 & 6.65 & 8.99 & 50.55 & 48.04 & 2.51 & 7.50 & 8.28 \\
\hline 3.4 & 65.61 & 48.21 & 17.4 & 6.24 & 8.89 & 52.03 & 50.1 & 1.93 & 7.29 & 8.00 \\
\hline 3.6 & 66.99 & 49.74 & 17.25 & 5.85 & 8.75 & 53.37 & 51.38 & 1.99 & 7.09 & 7.71 \\
\hline 3.8 & 68.07 & 51.76 & 16.31 & 5.51 & 8.56 & 55.26 & 53.13 & 2.13 & 6.94 & 7.43 \\
\hline 4.0 & 69.18 & 53.54 & 15.64 & 5.28 & 8.32 & 56.76 & 54.58 & 2.18 & 6.83 & 7.17 \\
\hline 4.2 & 69.93 & 54.8 & 15.13 & 5.20 & 8.03 & 57.81 & 59.89 & 1.92 & 6.81 & 6.94 \\
\hline 4.4 & 71.1 & 56.57 & 14.53 & 5.32 & 7.68 & 59.45 & 57.27 & 2.18 & 6.89 & 6.77 \\
\hline 4.6 & 71.9 & 57.98 & 13.92 & 5.71 & 7.27 & 60.3 & 58.47 & 1.83 & 7.09 & 6.66 \\
\hline 4.8 & 73.55 & 59.46 & 14.09 & 6.43 & 6.80 & 62.08 & 59.97 & 2.11 & 7.45 & 6.65 \\
\hline 5.0 & 74.83 & 60.76 & 14.07 & 7.56 & 6.27 & 63.64 & 61.29 & 2.35 & 8.01 & 6.75 \\
\hline
\end{tabular}
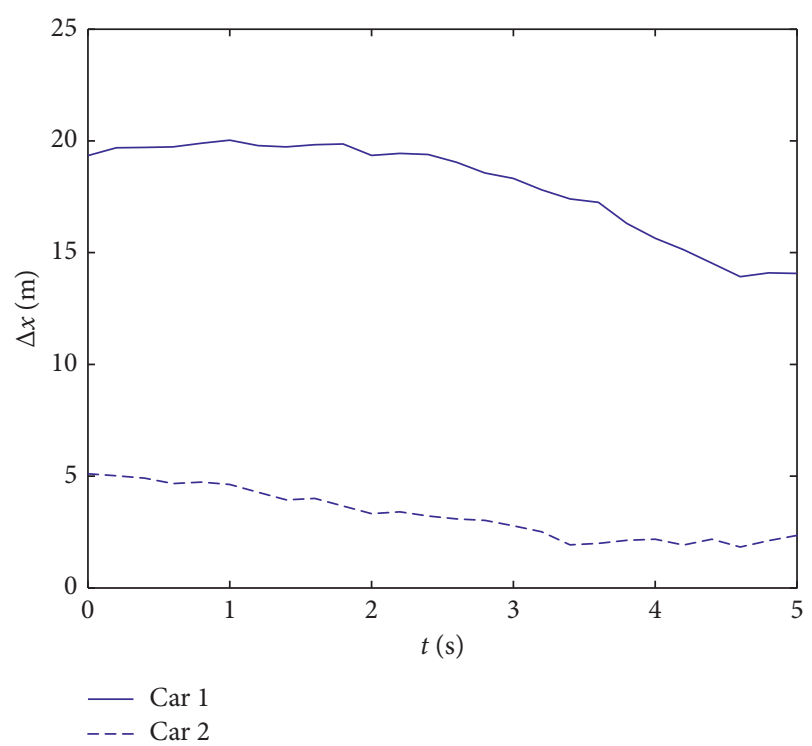

(a)

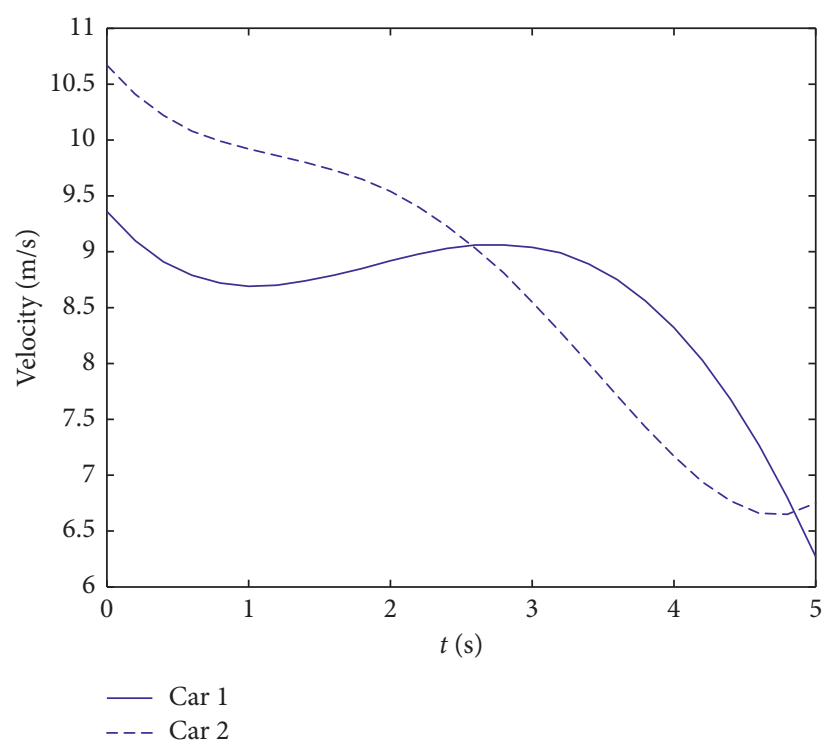

(b)

Figure 2: Traffic data of car 1 and car 2: (a) headway-time curves of car 1 and car 2; (b) velocity-time curves of car 1 and car 2.

Before the simulation, the parameters in OVM and FVDM need to be fitted. Parameters of OVM are the sensitivity coefficient $a$, maximum velocity of vehicle $v_{\max }$, and safety distance $h c$. Parameters of FVDM are, respectively, $a$, $h c$, and the sensitivity of velocity difference $\lambda$. The measured data of car 2 in Figure 1 can be used for parameter fitting because it is in accordance with most of vehicles' driving rules which are described by classic car-following models. 
The results of fitting are $a=0.0877, v_{\max }=16.7$, and $h c=$ 6.9781 for OVM, and $a=0.0593, h c=13.0123$, and $\lambda=0.4332$ for FVDM. Substituting above parameters into OVM and FVDM, respectively, to simulate the velocity of car 1 and comparing the simulation result with real velocity, we can obtain Figure 3.

From Figure 3, we can see that there is a large error between the simulation results of the two classic car-following models and this set of traffic data for car 1 . The simulation velocities of OVM continuously increase with the increase of headway. The difference between simulation velocity of FVDM and the velocity curve of car 1 keeps a larger value. Moreover, the variation trend of simulation velocity is opposite to that of real velocity after $t=3.8$ seconds, which means an increasing error.

From the perspective of model structure, OVM only considers the influence of headway, and FVDM takes into account the influence of both headway and velocity difference between the following vehicle and its preceding vehicle. The previous studies indicate that besides the influence of the leading vehicle, the driving behavior also can be affected by the lateral adjacent vehicle. However, both OVM and FVDM did not consider the factors of lateral influence. With above consideration, new improved carfollowing models accounting for the lateral influence are proposed in the next section. In Section 6, new improved models are validated by multiple sets of measured traffic data.

\section{Model}

The second-order car-following model belongs to the stimulus response model, which can be expressed as follows:

$$
\frac{\mathrm{d}^{2} x_{j}}{\mathrm{~d} t^{2}}(t)=f_{\mathrm{sti}}\left(v_{j}(t), \Delta x_{j}(t), \Delta v_{j}(t)\right) .
$$

Equation (3) expresses that the $j$ th vehicle's acceleration depends on speed of the $j$ th vehicle, the headway, and relative velocity between the $j$ th vehicle and the $(j+1)$ th vehicle. $f_{\text {sti }}$ represents response of the $j$ th vehicle to the $(j+1)$ th vehicle. Real driving behavior is determined mainly by the following two motivations: achieving an expectation speed and maintaining an expected distance [22].

By using the general force framework, we, respectively, put forward two improved car-following models, named model 1 and model 2, and compared to choose the optimum model.

The new improved model with the general force framework can be expressed as follows:

$$
\frac{\mathrm{d}^{2} x_{j}}{\mathrm{~d} t^{2}}(t)=f_{j}^{+}(t)+f_{j}^{-}(t)
$$

where $f_{j}^{+}(t)$ and $f_{j}^{-}(t)$ represent the influence of the leading car and the lateral vehicle's effect, respectively. Because of mainly depending on $\Delta x_{j}(t), f_{j}^{+}(t)$ can be expressed as OVM. $f_{j}^{-}(t)$ is determined by the impact of lateral adjacent vehicle and plays a role only when headway $\Delta x_{j}(t)$ is in a certain range. When $h c>\Delta x_{j}(t)$, in order to avoid the

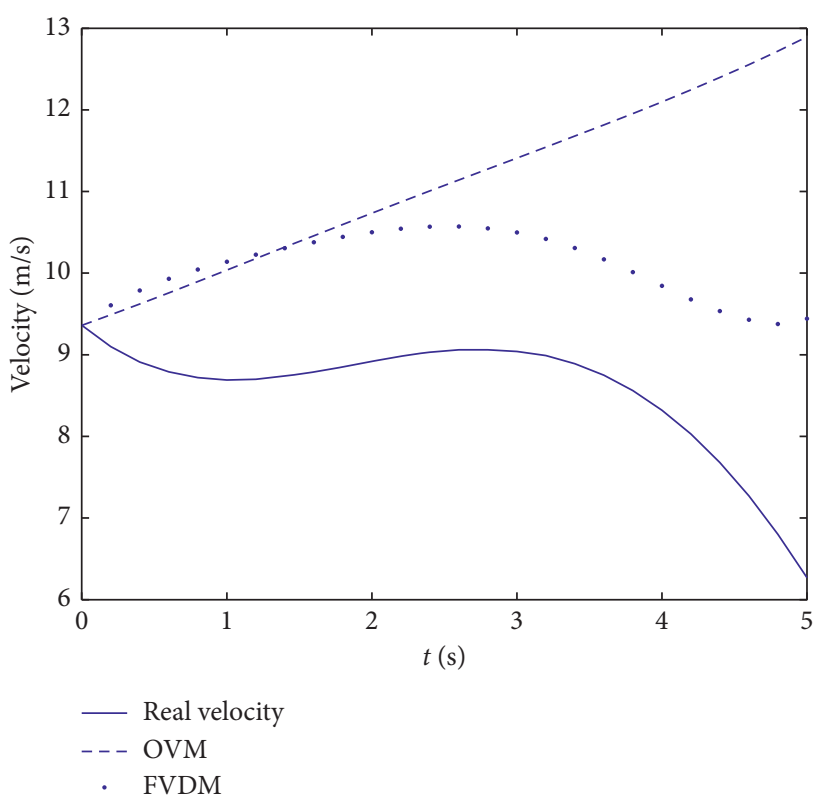

Figure 3: Comparison between simulation curves of classic carfollowing models and the curve of real velocity.

danger of collision, the driver often neglects the influence of lateral vehicle and changes the velocity to increase the headway. Only when $h c<\Delta x_{j}(t)$, the driver will consider the lateral effect.

$f_{j}^{-}(t)$ can be defined as

$$
f_{n}^{-}(t)=\gamma^{*} \frac{\mathrm{d}^{2} x_{j}^{\prime}(t)}{\mathrm{d} t^{2}}
$$

where $x_{j}^{\prime}(t)$ represents the position of the $j$ th vehicle's lateral adjacent vehicle. Obviously, lateral vehicles can play an auxiliary reference role only under certain conditions; for example, the relative speed between the investigated car and the lateral car is larger, or the distance is far. Therefore, we set the parameter $\gamma=\left\{\operatorname{const}\left|\Delta \bar{v}_{j}(t)\right|<\zeta v_{j}(t)\right.$ or $\left|\Delta \bar{x}_{j}(t)\right|<$ $\Delta x_{j}^{\prime}(t), 0$, other, where $\Delta x_{j}^{\prime}(t)=x_{j+1}^{\prime}(t)-x_{j}^{\prime}(t)$ is the headway between the $j$ th vehicle's lateral adjacent vehicle and its leading vehicle. $\Delta \bar{x}_{j}(t)=x_{j}^{\prime}(t)-x_{j}(t)$ and $\Delta \bar{v}_{j}$ $(t)=\left(\mathrm{d} x_{j}^{\prime}(t) / \mathrm{d} t\right)-\left(\mathrm{d} x_{j}(t) / \mathrm{d} t\right)$, respectively, represent the headway and velocity difference between the $j$ th vehicle and its lateral adjacent vehicle. $0<\zeta \leq 0.1$ is a constant. Thus, the first improved model (model 1) is given as follows:

$$
\frac{\mathrm{d}^{2} x_{j}(t)}{\mathrm{d} t^{2}}=a\left[V\left(\Delta x_{j}(t)\right)-\frac{\mathrm{d} x_{j}(t)}{\mathrm{d} t}\right]+\gamma^{*} \frac{\mathrm{d}^{2} x_{j}^{\prime}(t)}{\mathrm{d} t^{2}} \text {. }
$$

According to Reference [25], the second improved model (model 2) can be defined as

$$
\frac{\mathrm{d}^{2} x_{j}(t)}{\mathrm{d} t^{2}}=(1-P)^{*} a\left[V\left(\Delta x_{j}(t)\right)-\frac{\mathrm{d} x_{j}(t)}{\mathrm{d} t}\right]+p^{*} \frac{\mathrm{d}^{2} x_{j}^{\prime}(t)}{\mathrm{d} t^{2}},
$$

where $0 \leq p \leq 1$ is a coefficient which represents the weight of lateral effect. When $p=0$, equation (7) is reduced to the OVM. It means that the driver is completely unaffected by 
the lateral vehicle, and the driving state is determined only by the driving state of the leading vehicle. When $p=1$, the driver is only affected by lateral vehicle, and the vehicle exits the state of car-following.

Next, the two improved models are verified by the measured data to select the optimal model. In this paper, the least square method is used for parameter fitting. Result of fitting is as follows: $a=0.0877, h c=6.9781, p=0.7993$, and $\gamma=1.0246$. The fitted parameters are taken into the models, and velocity of the vehicle is simulated by the two improved models. Simulation results are compared with the actual data in Figure 4.

Figure 4 shows the comparison between simulation results of improved models and a set of traffic data for car 1 in Figure 1. The solid line is the curve of real velocity data, and the dashed line is the simulation result obtained by using the improved models. From Figure 4, we can find that for the data of car 1 in Figure 1, the curve of simulated velocity by using the first improved model has an increasing deviation from the real velocity after 3.6 seconds, while the curve obtained by the second improved model is close to the measured velocity curve during most of the time.

\section{The Linear Stability Analysis}

The linear stability theory is applied to derive linear stability condition of the improved model by the linear stability theory. The uniform traffic flow is defined by such a state that all vehicles on lane $l$ move with the optimal velocity $V_{l}\left(\Delta x_{l, n}(t)\right)$ and the identical headway $h_{l}$. The solution $x_{l, j}^{(0)}(t)$ is given by

$$
x_{l, j}^{(0)}(t)=h_{l}+V\left(h_{l}\right) t,
$$

where $l=1,2, h_{l}=D / N_{l}, D$ is length of road section, and $N_{l}$ represents the total number of vehicles in lane $l$. Assuming $x_{l, j}(t)=x_{l, j}^{(0)}(t)+y_{l, j}(t)$, where $x_{l, j}^{(0)}(t)=h_{l}+V\left(h_{l}\right) t$, and $y_{l, j}(t)$ be a small deviation from the steady state $x_{l, j}^{(0)}(t)$, then we can rewrite the two improved models (equations (6) and (7)) as

$$
\begin{aligned}
& \frac{\mathrm{d}^{2} y_{l, j}(t)}{\mathrm{d} t^{2}}=a_{l}\left[V^{\prime}\left(h_{l}\right) \Delta y_{l, j}(t)-\frac{\mathrm{d} y_{l, j}(t)}{\mathrm{d} t}\right]+\gamma \frac{\mathrm{d}^{2} y_{l^{\prime}, j}(t)}{\mathrm{d} t^{2}}, \\
& \frac{\mathrm{d}^{2} y_{l, j}(t)}{\mathrm{d} t^{2}}=(1-p) a_{l}\left[V^{\prime}\left(h_{l}\right) \Delta y_{l, j}(t)-\frac{\mathrm{d} y_{l, j}(t)}{\mathrm{d} t}\right]+p \frac{\mathrm{d}^{2} y_{l^{\prime}, j}(t)}{\mathrm{d} t^{2}},
\end{aligned}
$$

where $\Delta y_{l, j}(t)=y_{l, j+1}(t)-y_{l, j}(t), \quad y_{l^{\prime}, j}(t)=y_{3-l, j}(t)$. For convenience of calculation, we set $y_{3-l, j}(t)=\mu y_{l, j}, \mu=h_{3-l} l$ $h_{l}$. Expanding $y_{l, j}(t)$ in the Fourier-modes $y_{l, j}(t) \propto \exp$ $\left(i k_{l} j+z_{l} t\right)$, we have

$$
\begin{array}{r}
z_{l}^{2}(1-\mu \gamma)-a_{l}\left[V^{\prime}\left(h_{l}\right)\left(\exp \left(i k_{l}\right)-1\right)-z_{l}\right]=0, \\
z_{l}^{2}(1-\mu p)-(1-p) a_{l}\left[V^{\prime}\left(h_{l}\right)\left(\exp \left(i k_{l}\right)-1\right)-z_{l}\right]=0 .
\end{array}
$$

Substituting $z_{l}=z_{1 l}(i k)+z_{2 l}(i k)^{2}+\cdots$ into equations (10) and (11), we obtain the first- and second-order terms of coefficients in the expression of $z_{l}$ as follows:

$$
\begin{aligned}
& z_{1 l}=V^{\prime}\left(h_{l}\right), \\
& z_{2 l}=\frac{V^{\prime}\left(h_{l}\right)}{2}-\frac{(1-\mu \gamma) V^{\prime 2}\left(h_{l}\right)}{a_{l}}, \\
& z_{1 l}=V^{\prime}\left(h_{l}\right), \\
& z_{2 l}=\frac{V^{\prime}\left(h_{l}\right)}{2}-\frac{(1-\mu p) V^{\prime 2}\left(h_{l}\right)}{a_{l}(1-p)} .
\end{aligned}
$$

According to the long wave theory, the uniform steady state will become unstable when $z_{2 l}$ is negative. Thus, the neutral stability curves for model 1 and model 2 are given by

$$
\begin{aligned}
& a_{l s}=2(1-\mu \gamma) V^{\prime}\left(h_{l}\right), \\
& a_{l s}=\frac{2(1-\mu p) V^{\prime}\left(h_{l}\right)}{1-p} .
\end{aligned}
$$

For model 1, the uniform traffic flow will be stable if

$$
a_{l}>2(1-\mu \gamma) V^{\prime}\left(h_{l}\right) \text {. }
$$

For model 2, the uniform traffic flow will be stable if

$$
a_{l}>\frac{2(1-\mu p) V^{\prime}\left(h_{l}\right)}{1-p} \text {. }
$$

When $\gamma=0$ and $P=0$, the stability condition (equations (15) and (16)) is reduced to the stability condition in the literature [3].

Figure 5 shows the neutral stability line in the headwaysensitivity space $\left(\Delta x, a_{l}\right)$ with $\mu=0.5$ and different sets of parameters of lateral influence, where (a) and (b) are, respectively, for model 1 and model 2. The apex of each curve represents the critical point $\left(h c, a_{l c}\right)$. It can be seen clearly from Figure 5(a) that for model 1, the critical points decrease with increasing $\gamma$. It means that with decrease of lateral influence, traffic flow is more stable. On the contrary, from Figure 5(b), we can find that critical points rise with increasing $p$. It is in accordance with common sense that lateral interference can affect driving.

\section{Nonlinear Analysis}

In this section, nonlinear analysis is carried out to investigate the traffic performances near the critical point $\left(h_{c}, a_{c}\right)$ of improved car-following model 2 . The $\mathrm{mKdV}$ equation is deduced to describe the traffic congestion in the unstable area of traffic flow. For extracting slow scales with the space variable $n$ and the time variable $t$, the slow variables $X$ and $T$ are defined as follows:

$$
\begin{aligned}
X & =(j+b t), \\
T & =\varepsilon^{3} t,
\end{aligned}
$$




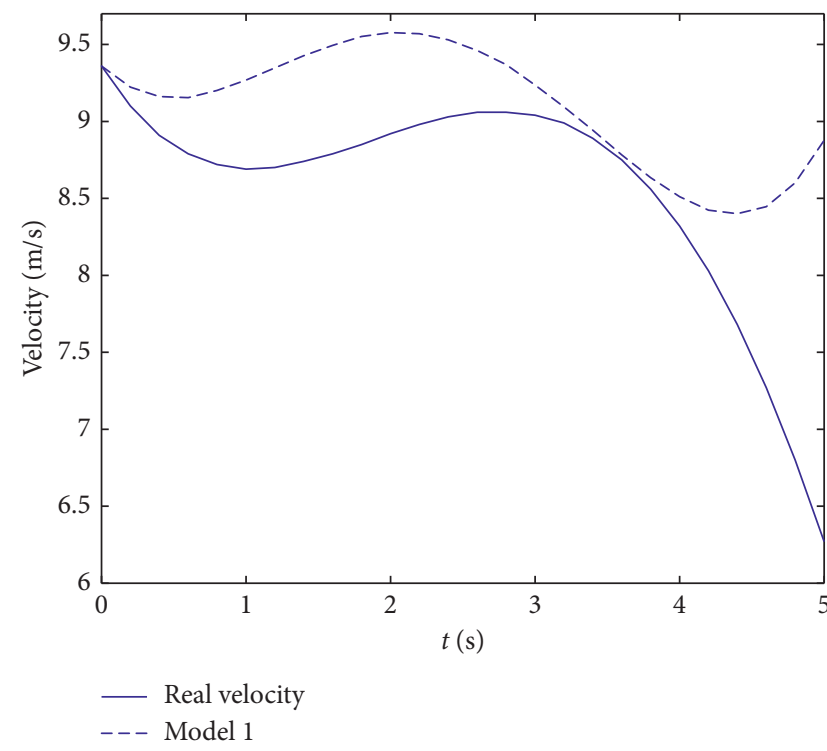

(a)

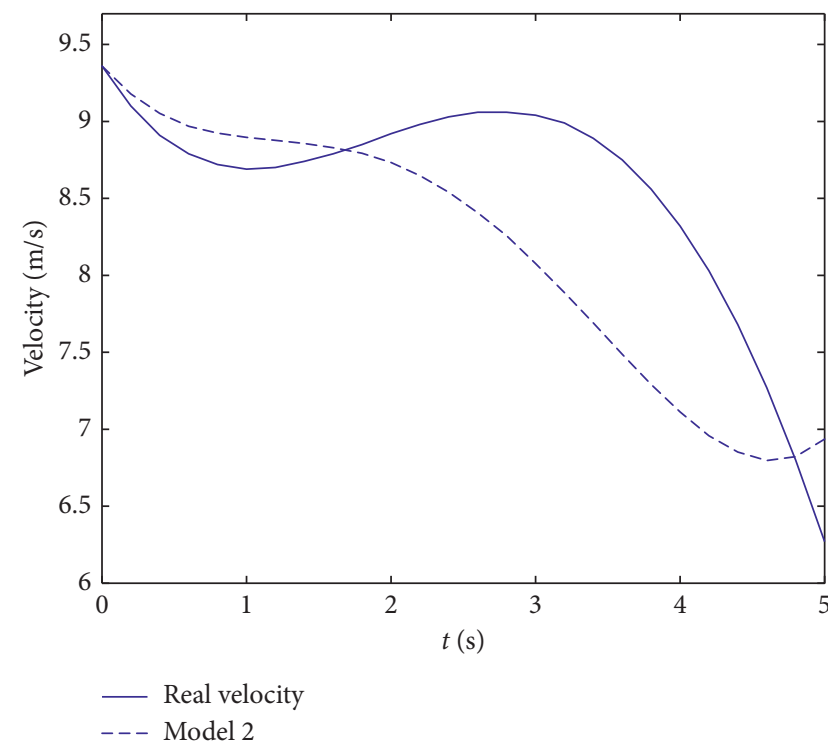

(b)

FIGURE 4: Comparison between simulation curves of improved models and the curve of real velocity: (a) velocity-time curves of improved model 1; (b) velocity-time curves of improved model 2.

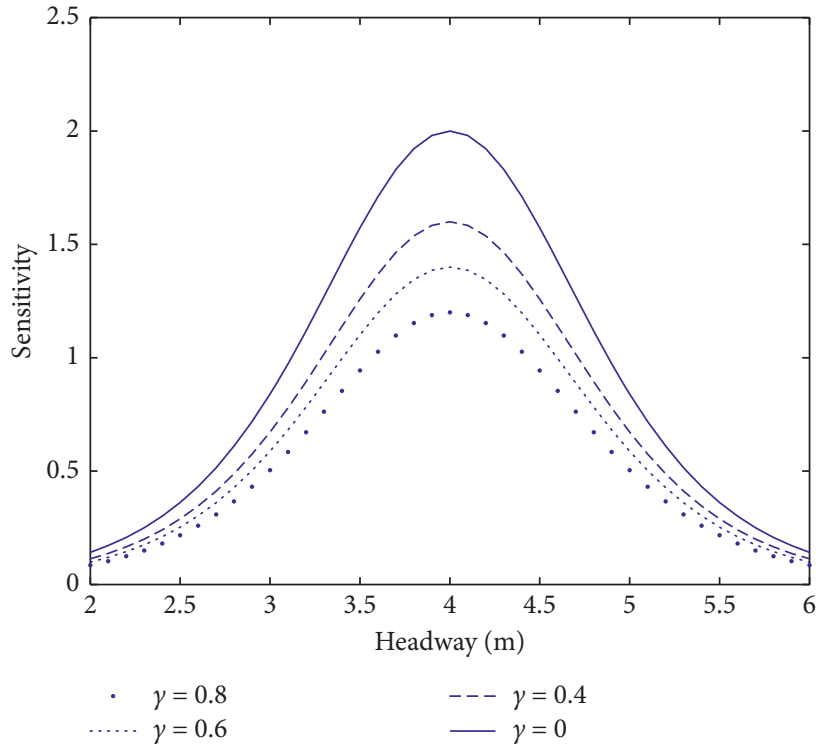

(a)

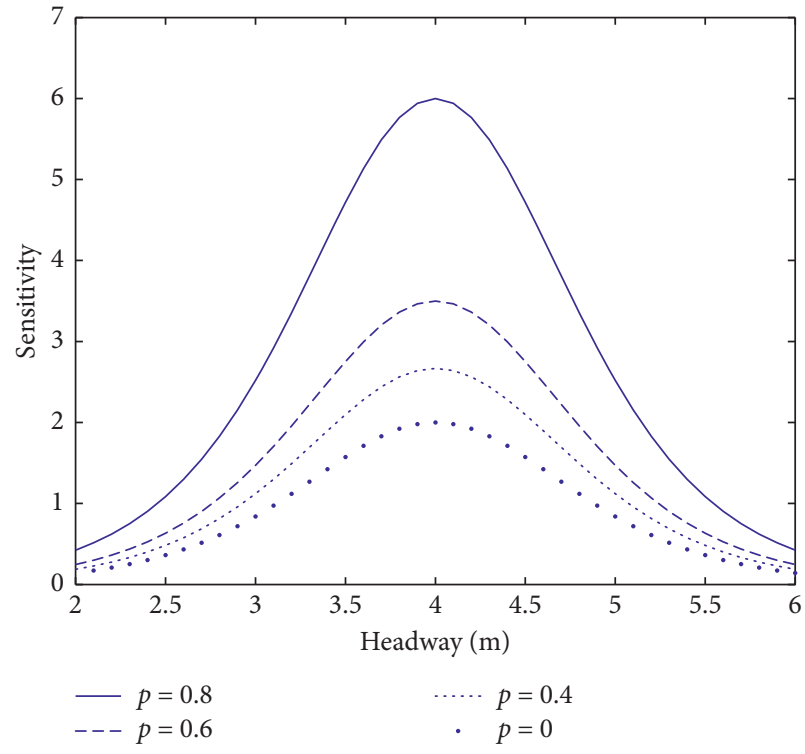

(b)

FIGURE 5: Critical stability curves: (a) for model 1; (b) for model 2.

where $b$ is a constant to be determined. We set the headway as

$$
\Delta x_{n}(t)=h_{c}+\varepsilon R(X, T) .
$$

We rewrite equation (7) as follows:

$$
\begin{aligned}
\frac{\mathrm{d}^{2} \Delta x_{j}(t)}{\mathrm{d} t^{2}}= & (1-p) a\left[V\left(\Delta x_{j+1}(t)\right)-V\left(\Delta x_{j}(t)\right)\right. \\
& \left.--\frac{\mathrm{d} \Delta x_{j}(t)}{\mathrm{d} t}\right]+p \frac{\mathrm{d}^{2} \Delta x_{j}^{\prime}(t)}{\mathrm{d} t^{2}}
\end{aligned}
$$

For convenience of calculation, we assume that the vehicles around the investigated vehicle are in normal driving process and have similar driving state. Therefore, the driving condition of the lateral vehicle can be approximately expressed by that of other vehicles around it. In view of above considerations, we set $\left(\mathrm{d}^{2} \Delta x_{j}^{\prime}(t) / \mathrm{d} t^{2}\right)=\lambda_{1}\left(\mathrm{~d}^{2} \Delta x_{j+1}\right.$ $\left.(t) / \mathrm{d} t^{2}\right)+\lambda_{2}\left(\mathrm{~d}^{2} \Delta x_{j-1}(t) / \mathrm{d} t^{2}\right)$, where $\lambda_{1}$ and $\lambda_{2}$ are constant, and $\lambda_{1}+\lambda_{2}=1$. Substituting equations (17) and (18) into equation (19) and making the Taylor expansion to the fifth order of $\varepsilon$ lead to the following expression: 


$$
\begin{aligned}
& \varepsilon^{2} a(1-p)\left(b-V^{\prime}(h)\right) \partial_{X} R+\varepsilon^{3}\left[b^{2}-\frac{1}{2} a(1-p) V^{\prime}(h)-p b^{2}\right] \partial_{X}^{2} R \\
& \quad+\varepsilon^{4}\left[a(1-p)\left(\partial_{T} R-\frac{1}{6} V^{\prime}(h) \partial_{X}^{3} R-\frac{1}{6} V^{\prime \prime \prime}(h) \partial_{X} R^{3}\right)-p\left(\lambda_{1}-\lambda_{2}\right) b^{2} \partial_{X}^{3} R\right] \\
& \quad+\varepsilon^{5}\left[2 b(1-p) \partial_{T} \partial_{X} R-\frac{1}{2} b^{2} \partial_{X}^{4} R-a(1-p)\left(\frac{1}{24} V^{\prime}(h) \partial_{X}^{4} R+\frac{1}{12} V^{\prime \prime \prime}(h) \partial_{X}^{2} R^{3}\right)\right] .
\end{aligned}
$$

Near the critical point $\left(h_{c}, a_{c}\right)$, taking $a_{c} / a=\left(1+\varepsilon^{2}\right)$, $b=V^{\prime}\left(h_{c}\right)$, and eliminating both the second-order and the third-order term of $\varepsilon$, equation (14) can be simplified as

$$
\partial_{T} R-g_{1} \partial_{X}^{3} R+g_{2} \partial_{X}^{3} R+\varepsilon\left[g_{3} \partial_{X}^{2} R+g_{4} \partial_{X}^{4} R+g_{5} \partial_{X}^{2} R^{3}\right]=0,
$$

where

$$
\begin{aligned}
& g_{1}=\left(\frac{1}{6}+\frac{p\left(\lambda_{1}-\lambda_{2}\right) V^{\prime}}{a(1-p)}\right) V^{\prime}, \\
& g_{2}=-\frac{1}{6} V^{\prime \prime \prime}, \\
& g_{3}=-\frac{1}{2} V^{\prime} \\
& g_{4}=\frac{\left(4 V^{\prime}-a\right)}{12 a} V^{\prime \prime \prime}, \\
& g_{5}=\left(\frac{V^{\prime}}{3 a}+\frac{2 p\left(\lambda_{1}-\lambda_{2}\right)}{a^{2}(1-p)} V^{\prime 2}-\frac{V^{\prime}}{2 a(1-p)}-\frac{1}{24}\right) V^{\prime} .
\end{aligned}
$$

Making such transformations as $T=\left(1 / g_{1}\right) T_{m}$ and $R=\sqrt{g_{1} / g_{2}} R_{m}$, we obtain the modified KDV equation with a $o(\varepsilon)$ correction term:

$$
\begin{aligned}
\partial_{T} R_{m} & -\partial_{X}^{3} R_{m}+g_{2} \partial_{X} R_{m}^{3} \\
& +\frac{\varepsilon}{g_{1}}\left[g_{3} \partial_{X}^{2} R_{m}+g_{4} \partial_{X}^{4} R_{m}+\frac{g_{1} g_{5}}{g_{2}} \partial_{X}^{2} R_{m}^{3}\right]=0 .
\end{aligned}
$$

If we ignore $o(\varepsilon)$ term, this is just the modified KDV equation, and the solution is as follows:

$$
R(X, T)=\sqrt{\frac{g_{1}}{g_{2}} B} \tanh \left[\sqrt{\frac{B}{2}}\left(X-B g_{1} T\right)\right],
$$

where $B=\left(5 g_{2} g_{3} / 2 g_{2} g_{4}-3 g_{1} g_{5}\right)$.Thus, we obtain the kink solution of the headway:

$$
\begin{aligned}
\Delta x_{n}(t)= & h_{c}+\sqrt{\frac{g_{1} B}{g_{2}}\left(\frac{a_{c}}{a}-1\right)} \times \tanh \left\{\sqrt{\frac{B}{2}\left(\frac{a_{c}}{a}-1\right)}\right. \\
& \left.\times\left[n+V^{\prime}\left(h_{c}\right) t-B g_{1}\left(\frac{a_{c}}{a}-1\right) t\right]\right\} .
\end{aligned}
$$

\section{Numerical Simulations}

6.1. Model Validation with Measured Data. In this subsection, the OVM and improved models are, respectively, verified by using real traffic data. The traffic data can be seen in Tables $2-5$. The model parameters need to be fitted by using the least square method. Due to the difference of driving behavior, the model parameters obtained from different sets of data are different. Hence, the data of each group need to be fitted, respectively, and the fitting results are shown in Table 6.

The skewness test and kurtosis test of the fitted parameters are carried out. $U_{1}$ and $U_{2}$ are, respectively, denote sample skewness and sample kurtosis of the fitted parameters. Calculation results for skewness and kurtosis are shown in Table 7.

We set the significant level as $\alpha=0.05$, so the reject region is $(-\infty, 1.96) \cup(1.96,+\infty)$. From Table 2 , it can be seen that the calculation results of $U_{1}$ and $U_{2}$ are all outside the reject region. Therefore, the fitted parameters obey normal distribution.

In order to compare the performance of the models, we substitute the fitted parameters into OVM and two improved models, respectively, carry out simulation by using the three models, and then obtain the curves of velocity. Comparing the simulation curves with the measured velocity curve, we obtain Figure 6.

In Figure 6, real line is the measured velocity of vehicle, "." represents the curve of OVM, and "+" and " * " denote the curve of improved model 1 and model 2, respectively. The simulation results show that the velocity curves of the two improved models are more close to the real velocity than that of the OVM and that in the comparison of the two improved models, and the velocity curve of the improved model 2 is closer to the actual speed.

In this paper, the following three performance indexes are used to evaluate the simulation results: the mean square error, the maximum absolute error, and the minimum absolute error.

Table 8 shows the comparison of three performance evaluation indices for each group of data. From Table 8, we can find that for mean square deviation and maximum absolute error, numerical values of OVM are the largest in four sets of data, while the numerical values of improved model 2 are the smallest. Moreover, least absolute errors of improved model 1 are larger than that of OVM in the $1^{\text {st }}$ and $3^{\text {rd }}$ sets of data, while improved model 2 has the smallest least absolute errors in all four sets of data. Compared with the OVM, the simulation result of improved model 2, respectively, gets $62.89 \%$ unbiased variance reduction, $66.39 \%$ maximum absolute error reduction, and $33.4 \%$ minimum absolute error reduction, while that of improved model 1 only gets $27.53 \%$ unbiased variance reduction, $28.4 \%$ 
TABLE 2: The first sets of vehicle data.

\begin{tabular}{|c|c|c|c|c|c|c|c|c|}
\hline \multirow[b]{2}{*}{ Time (s) } & \multicolumn{4}{|c|}{ The left lane } & \multicolumn{4}{|c|}{ The right lane } \\
\hline & $\begin{array}{l}\text { Position of } \\
\text { leading car }\end{array}$ & $\begin{array}{l}\text { Position of } \\
\text { following car }\end{array}$ & Headway & $\begin{array}{l}\text { Velocity of } \\
\text { following car }\end{array}$ & $\begin{array}{l}\text { Position of } \\
\text { leading car }\end{array}$ & $\begin{array}{c}\text { Position of following } \\
\text { car }\end{array}$ & Headway & $\begin{array}{l}\text { Velocity of following } \\
\text { car }\end{array}$ \\
\hline 0 & 26.22 & 18.93 & 7.29 & 6.85 & 40.71 & 18.27 & 22.44 & 8.43 \\
\hline 0.2 & 27.85 & 20.5 & 7.35 & 6.86 & 42.65 & 20.18 & 22.47 & 8.30 \\
\hline 0.4 & 29.02 & 21.56 & 7.46 & 6.84 & 43.76 & 21.46 & 22.3 & 8.19 \\
\hline 0.6 & 30.65 & 23.17 & 7.48 & 6.79 & 45.54 & 23.45 & 22.09 & 8.11 \\
\hline 0.8 & 31.61 & 24.24 & 7.37 & 6.72 & 46.81 & 24.68 & 22.13 & 8.04 \\
\hline 1.0 & 33.2 & 25.82 & 7.38 & 6.63 & 48.66 & 26.55 & 22.11 & 7.99 \\
\hline 1.2 & 34.5 & 27.15 & 7.35 & 6.54 & 50.29 & 28.18 & 22.11 & 7.94 \\
\hline 1.4 & 35.8 & 28.43 & 7.37 & 6.45 & 51.84 & 29.73 & 22.11 & 7.91 \\
\hline 1.6 & 36.99 & 29.78 & 7.21 & 6.36 & 53.26 & 31.38 & 21.88 & 7.88 \\
\hline 1.8 & 37.94 & 30.82 & 7.12 & 6.28 & 54.33 & 32.64 & 21.69 & 7.86 \\
\hline 2.0 & 39.28 & 32.01 & 7.27 & 6.21 & 55.9 & 34.17 & 21.73 & 7.84 \\
\hline 2.2 & 40.83 & 33.55 & 7.28 & 6.16 & 57.56 & 36.2 & 21.36 & 7.82 \\
\hline 2.4 & 41.85 & 34.5 & 7.35 & 6.12 & 58.81 & 37.4 & 21.41 & 7.79 \\
\hline 2.6 & 43.62 & 36 & 7.62 & 6.10 & 60.65 & 39.21 & 21.44 & 7.77 \\
\hline 2.8 & 44.78 & 37.1 & 7.68 & 6.09 & 62.03 & 40.75 & 21.28 & 7.74 \\
\hline 3.0 & 45.85 & 38.17 & 7.68 & 6.10 & 63.48 & 41.92 & 21.56 & 7.70 \\
\hline 3.2 & 47.63 & 39.53 & 8.1 & 6.13 & 64.99 & 43.82 & 21.17 & 7.66 \\
\hline 3.4 & 49.02 & 40.74 & 8.28 & 6.17 & 66.26 & 45.32 & 20.94 & 7.61 \\
\hline 3.6 & 50.48 & 42.02 & 8.46 & 6.22 & 67.91 & 46.78 & 21.13 & 7.55 \\
\hline 3.8 & 51.84 & 43.39 & 8.45 & 6.27 & 69.29 & 48.34 & 20.95 & 7.48 \\
\hline 4.0 & 53.05 & 44.4 & 8.65 & 6.33 & 70.37 & 49.5 & 20.87 & 7.40 \\
\hline 4.2 & 54.77 & 45.77 & 9 & 6.39 & 71.85 & 51.26 & 20.59 & 7.31 \\
\hline 4.4 & 56.13 & 46.9 & 9.23 & 6.43 & 72.62 & 52.56 & 20.06 & 7.22 \\
\hline 4.6 & 57.81 & 48.44 & 9.37 & 6.46 & 74.2 & 54.14 & 20.06 & 7.12 \\
\hline 4.8 & 59.32 & 49.7 & 9.62 & 6.47 & 75.43 & 55.81 & 19.62 & 7.01 \\
\hline 5.0 & 60.38 & 50.84 & 9.54 & 6.44 & 76.7 & 56.69 & 20.01 & 6.89 \\
\hline 5.2 & 61.75 & 52.23 & 9.52 & 6.38 & 77.13 & 58.3 & 18.83 & 6.77 \\
\hline
\end{tabular}

TABLE 3: The second sets of vehicle data.

\begin{tabular}{|c|c|c|c|c|c|c|c|c|}
\hline \multirow[b]{2}{*}{ Time (s) } & \multicolumn{4}{|c|}{ The left lane } & \multicolumn{4}{|c|}{ The right lane } \\
\hline & $\begin{array}{l}\text { Position of } \\
\text { leading car }\end{array}$ & $\begin{array}{c}\text { Position of } \\
\text { following ca }\end{array}$ & Headway & $\begin{array}{l}\text { Position of } \\
\text { leading car }\end{array}$ & $\begin{array}{l}\text { Position of following } \\
\text { car }\end{array}$ & Headway & $\begin{array}{l}\text { Position of leading } \\
\text { car }\end{array}$ & $\begin{array}{c}\text { Position of following } \\
\text { car }\end{array}$ \\
\hline 0 & 22.5 & 17.21 & 5.29 & 8.09 & 35.89 & 19.07 & 16.82 & 9.35 \\
\hline 0.2 & 24.29 & 18.8 & 5.49 & 7.46 & 38.02 & 20.96 & 17.06 & 8.89 \\
\hline 0.4 & 26.03 & 20.44 & 5.59 & 7.02 & 40.13 & 22.97 & 17.16 & 8.60 \\
\hline 0.6 & 27.25 & 21.49 & 5.76 & 6.73 & 41.55 & 24.23 & 17.32 & 8.44 \\
\hline 0.8 & 29.08 & 23.08 & 6 & 6.57 & 43.55 & 26.22 & 17.33 & 8.38 \\
\hline 1.0 & 30.33 & 24.11 & 6.22 & 6.50 & 45.05 & 27.55 & 17.5 & 8.39 \\
\hline 1.2 & 31.93 & 25.45 & 6.48 & 6.49 & 46.82 & 29.31 & 17.51 & 8.44 \\
\hline 1.4 & 33.59 & 26.75 & 6.84 & 6.52 & 48.54 & 31.05 & 17.49 & 8.52 \\
\hline 1.6 & 35.42 & 28.35 & 7.07 & 6.57 & 50.58 & 33.08 & 17.5 & 8.60 \\
\hline 1.8 & 37.09 & 29.67 & 7.42 & 6.64 & 52.12 & 34.82 & 17.3 & 8.67 \\
\hline 2.0 & 38.53 & 30.72 & 7.81 & 6.70 & 53.5 & 36.2 & 17.3 & 8.72 \\
\hline 2.2 & 40.22 & 32.07 & 8.15 & 6.75 & 55.21 & 37.99 & 17.22 & 8.75 \\
\hline 2.4 & 42.33 & 33.69 & 8.64 & 6.79 & 57.02 & 39.96 & 17.06 & 8.76 \\
\hline 2.6 & 43.55 & 34.73 & 8.82 & 6.82 & 58.39 & 41.33 & 17.06 & 8.73 \\
\hline 2.8 & 45.67 & 36.38 & 9.29 & 6.84 & 60.41 & 43.55 & 16.86 & 8.69 \\
\hline 3.0 & 47.07 & 37.5 & 9.57 & 6.87 & 61.63 & 44.9 & 16.73 & 8.63 \\
\hline 3.2 & 48.75 & 38.9 & 9.85 & 6.91 & 63.21 & 46.63 & 16.58 & 8.58 \\
\hline 3.4 & 50.55 & 40.3 & 10.25 & 6.98 & 64.88 & 48.34 & 16.54 & 8.54 \\
\hline 3.6 & 52.47 & 41.92 & 10.55 & 7.11 & 66.27 & 50.36 & 15.91 & 8.54 \\
\hline 3.8 & 54.07 & 43.42 & 10.65 & 7.32 & 68.1 & 52.18 & 15.92 & 8.61 \\
\hline 4.0 & 55.75 & 44.62 & 11.13 & 7.63 & 69.24 & 53.54 & 15.7 & 8.77 \\
\hline 4.2 & 57.54 & 46.19 & 11.35 & 8.09 & 70.83 & 55.17 & 15.66 & 9.05 \\
\hline 4.4 & 59.73 & 48.02 & 11.71 & 8.72 & 72.48 & 57.37 & 15.11 & 9.49 \\
\hline
\end{tabular}


TABLE 4: The third sets of vehicle data.

\begin{tabular}{|c|c|c|c|c|c|c|c|c|}
\hline \multirow[b]{2}{*}{ Time (s) } & \multicolumn{4}{|c|}{ The left lane } & \multicolumn{4}{|c|}{ The right lane } \\
\hline & $\begin{array}{l}\text { Position of } \\
\text { leading car }\end{array}$ & $\begin{array}{l}\text { Position of } \\
\text { following car }\end{array}$ & Headway & $\begin{array}{l}\text { Position of } \\
\text { leading car }\end{array}$ & $\begin{array}{c}\text { Position of following } \\
\text { car }\end{array}$ & Headway & $\begin{array}{c}\text { Position of leading } \\
\text { car }\end{array}$ & $\begin{array}{c}\text { Position of following } \\
\text { car }\end{array}$ \\
\hline 0 & 39.86 & 19.14 & 20.72 & 9.62 & 24.11 & 17.48 & 6.63 & 9.62 \\
\hline 0.2 & 41.72 & 21.24 & 20.48 & 8.88 & 26.22 & 19.61 & 6.61 & 9.22 \\
\hline 0.4 & 43.34 & 22.94 & 20.4 & 8.40 & 27.97 & 21.46 & 6.51 & 9.01 \\
\hline 0.6 & 44.63 & 24.31 & 20.32 & 8.12 & 29.35 & 22.9 & 6.45 & 8.92 \\
\hline 0.8 & 46.16 & 25.99 & 20.17 & 7.98 & 31.09 & 24.76 & 6.33 & 8.93 \\
\hline 1.0 & 47.8 & 27.65 & 20.15 & 7.94 & 32.87 & 26.55 & 6.32 & 8.98 \\
\hline 1.2 & 49.19 & 29.37 & 19.82 & 7.96 & 34.59 & 28.4 & 6.19 & 9.05 \\
\hline 1.4 & 51.05 & 31.32 & 19.73 & 8.01 & 36.69 & 30.6 & 6.09 & 9.11 \\
\hline 1.6 & 52.44 & 32.64 & 19.8 & 8.06 & 37.94 & 32.07 & 5.87 & 9.15 \\
\hline 1.8 & 54.11 & 34.35 & 19.76 & 8.09 & 39.63 & 33.85 & 5.78 & 9.14 \\
\hline 2.0 & 55.44 & 35.93 & 19.51 & 8.08 & 41.47 & 35.67 & 5.8 & 9.09 \\
\hline 2.2 & 57.56 & 37.89 & 19.67 & 8.02 & 43.34 & 37.69 & 5.65 & 8.97 \\
\hline 2.4 & 58.81 & 39.53 & 19.28 & 7.92 & 45.08 & 39.53 & 5.55 & 8.80 \\
\hline 2.6 & 60.11 & 40.75 & 19.36 & 7.77 & 46.32 & 40.86 & 5.46 & 8.58 \\
\hline 2.8 & 61.75 & 42.41 & 19.34 & 7.59 & 47.97 & 42.53 & 5.44 & 8.33 \\
\hline 3.0 & 63.48 & 44.49 & 18.99 & 7.39 & 49.92 & 44.49 & 5.43 & 8.06 \\
\hline 3.2 & 64.69 & 45.75 & 18.94 & 7.18 & 51.25 & 45.89 & 5.36 & 7.80 \\
\hline 3.4 & 66.58 & 47.71 & 18.87 & 7.01 & 52.85 & 47.71 & 5.14 & 7.58 \\
\hline 3.6 & 67.91 & 49.16 & 18.75 & 6.91 & 54.11 & 49.16 & 4.95 & 7.42 \\
\hline 3.8 & 68.94 & 50.19 & 18.75 & 6.90 & 54.99 & 50.36 & 4.63 & 7.38 \\
\hline 4.0 & 70.73 & 51.99 & 18.74 & 7.05 & 56.84 & 51.99 & 4.85 & 7.49 \\
\hline 4.2 & 71.85 & 53.34 & 18.51 & 7.40 & 58.3 & 53.34 & 4.96 & 7.82 \\
\hline 4.4 & 73.8 & 55.39 & 18.41 & 8.01 & 59.84 & 55.17 & 4.67 & 8.41 \\
\hline
\end{tabular}

TABLE 5: The fourth sets of vehicle data.

\begin{tabular}{|c|c|c|c|c|c|c|c|c|}
\hline \multirow[b]{2}{*}{ Time (s) } & \multicolumn{4}{|c|}{ The left lane } & \multicolumn{4}{|c|}{ The right lane } \\
\hline & $\begin{array}{l}\text { Position of } \\
\text { leading car }\end{array}$ & $\begin{array}{l}\text { Position of } \\
\text { following car }\end{array}$ & Headway & $\begin{array}{l}\text { Position of } \\
\text { leading car }\end{array}$ & $\begin{array}{l}\text { Position of following } \\
\text { car }\end{array}$ & Headway & $\begin{array}{c}\text { Position of leading } \\
\text { car }\end{array}$ & $\begin{array}{c}\text { Position of following } \\
\text { car }\end{array}$ \\
\hline 0 & 36.38 & 16.42 & 19.96 & 10.50 & 26.35 & 16.53 & 9.82 & 10.14 \\
\hline 0.2 & 38.26 & 18.56 & 19.7 & 10.52 & 28.27 & 18.65 & 9.62 & 10.21 \\
\hline 0.4 & 39.98 & 20.64 & 19.34 & 10.53 & 30.13 & 20.73 & 9.4 & 10.19 \\
\hline 0.6 & 42.12 & 22.72 & 19.4 & 10.54 & 31.94 & 22.76 & 9.18 & 10.11 \\
\hline 0.8 & 44.05 & 24.85 & 19.2 & 10.53 & 33.86 & 24.7 & 9.16 & 9.97 \\
\hline 1.0 & 45.85 & 26.91 & 18.94 & 10.51 & 35.67 & 26.71 & 8.96 & 9.79 \\
\hline 1.2 & 47.63 & 29.05 & 18.58 & 10.47 & 37.41 & 28.56 & 8.85 & 9.60 \\
\hline 1.4 & 49.37 & 31.21 & 18.16 & 10.41 & 39.18 & 30.46 & 8.72 & 9.40 \\
\hline 1.6 & 51.25 & 33.17 & 18.08 & 10.34 & 40.97 & 32.32 & 8.65 & 9.21 \\
\hline 1.8 & 52.85 & 35.23 & 17.62 & 10.24 & 42.76 & 34.15 & 8.61 & 9.02 \\
\hline 2.0 & 54.77 & 37.36 & 17.41 & 10.12 & 44.21 & 36 & 8.21 & 8.85 \\
\hline 2.2 & 56.13 & 39.33 & 16.8 & 9.99 & 45.92 & 37.63 & 8.29 & 8.71 \\
\hline 2.4 & 57.56 & 41.65 & 15.91 & 9.84 & 47.95 & 40 & 7.95 & 8.58 \\
\hline 2.6 & 58.81 & 42.92 & 15.89 & 9.67 & 48.54 & 40.99 & 7.55 & 8.48 \\
\hline 2.8 & 60.92 & 45.12 & 15.8 & 9.49 & 50.58 & 42.97 & 7.61 & 8.40 \\
\hline 3.0 & 62.31 & 47.08 & 15.23 & 9.30 & 52.12 & 44.4 & 7.72 & 8.34 \\
\hline 3.2 & 64.08 & 48.88 & 15.2 & 9.10 & 53.74 & 46.25 & 7.49 & 8.29 \\
\hline 3.4 & 65.62 & 50.64 & 14.98 & 8.91 & 55.21 & 47.91 & 7.3 & 8.24 \\
\hline 3.6 & 67.24 & 52.34 & 14.9 & 8.72 & 56.76 & 49.51 & 7.25 & 8.18 \\
\hline 3.8 & 68.94 & 54.16 & 14.78 & 8.54 & 57.84 & 51.03 & 6.81 & 8.09 \\
\hline 4.0 & 70.73 & 56.34 & 14.39 & 8.39 & 59.53 & 52.64 & 6.89 & 7.97 \\
\hline 4.2 & 71.48 & 57.5 & 13.98 & 8.25 & 60.71 & 54.14 & 6.57 & 7.80 \\
\hline 4.4 & 73.01 & 58.96 & 14.05 & 8.16 & 62.25 & 56.19 & 6.06 & 7.55 \\
\hline 4.6 & 74.2 & 60.76 & 13.44 & 8.10 & 63.54 & 57.4 & 6.14 & 7.21 \\
\hline 4.8 & 75.85 & 62.39 & 13.46 & 8.10 & 64.88 & 58.67 & 6.21 & 6.75 \\
\hline 5.0 & 77.13 & 64.11 & 13.02 & 8.16 & 66.27 & 59.99 & 6.28 & 6.15 \\
\hline
\end{tabular}


TABLE 6: Fitting parameters in every sets of data.

\begin{tabular}{lccc}
\hline & $a$ & $h c$ & $\gamma$ \\
\hline The $1^{\text {st }}$ sets of data & 0.0233 & 8.4482 & 0.4259 \\
The $2^{\text {nd }}$ sets of data & 0.1544 & 9.0074 & 0.6004 \\
The $3^{\text {rd }}$ sets of data & 0.0298 & 16.6818 & 1.1886 \\
The $4^{\text {th }}$ sets of data & 0.1293 & 9.4227 & 0.9263 \\
\hline
\end{tabular}

TABLE 7: The skewness and kurtosis of the fitted parameters.

\begin{tabular}{ccccc}
\hline & $a$ & $h c$ & $\gamma$ & $p$ \\
\hline$U_{1}$ & 0.1091 & 1.9093 & 0.9596 & -0.9933 \\
$U_{2}$ & -1.1630 & 0.8365 & 0.2085 & 0.1299 \\
\hline
\end{tabular}

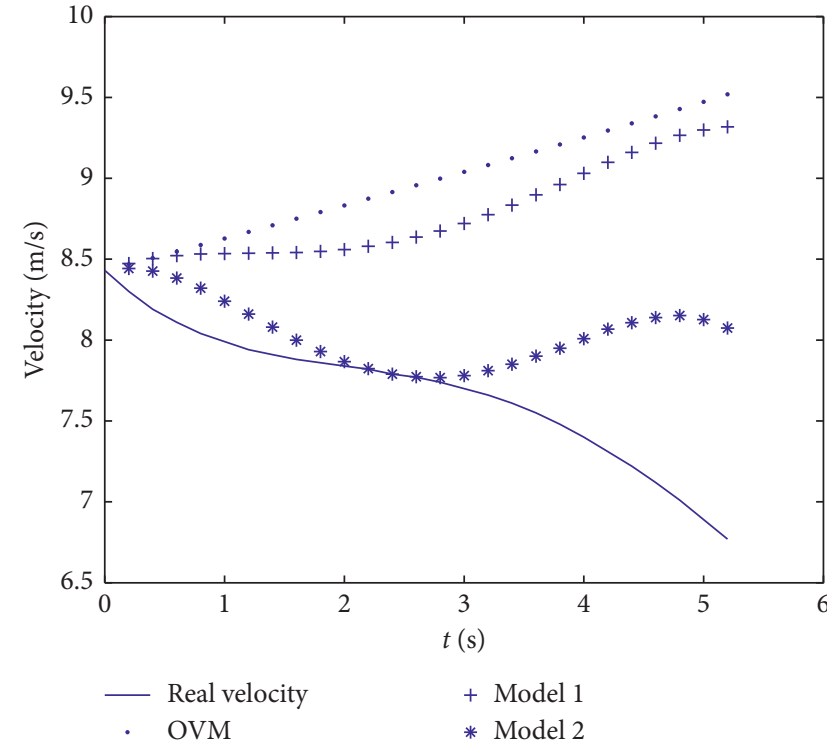

(a)

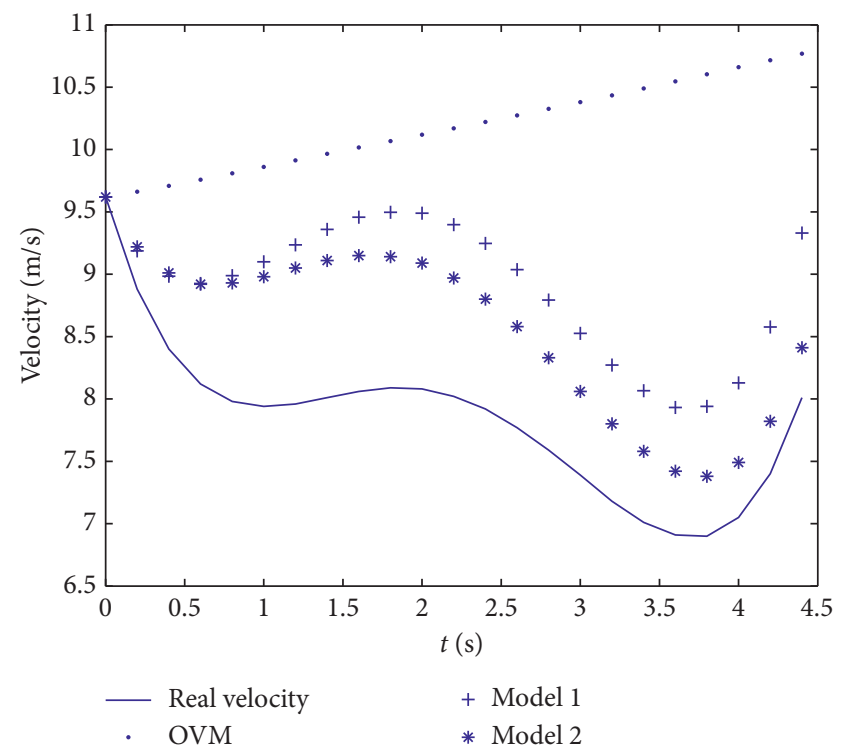

(c)

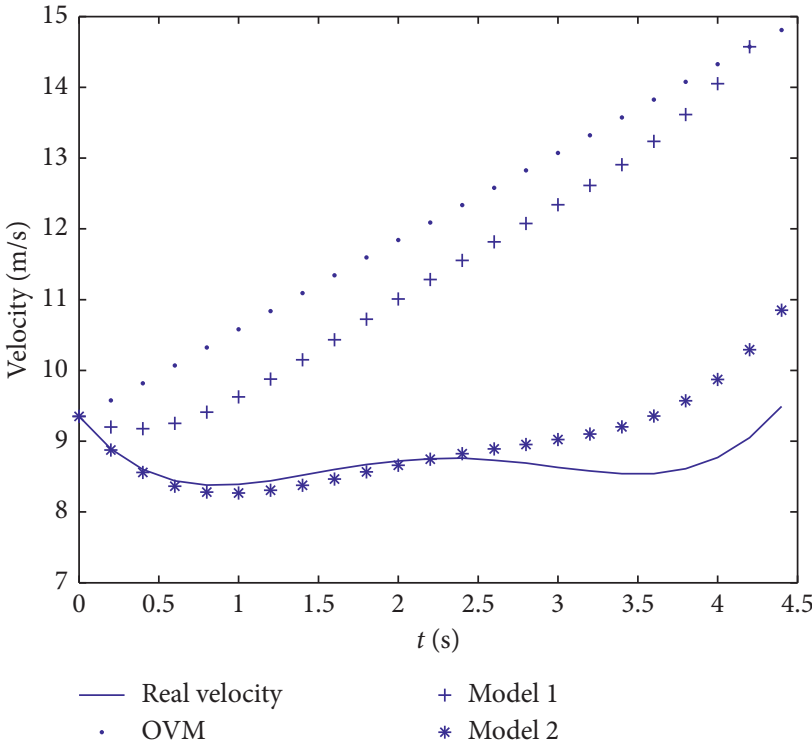

(b)

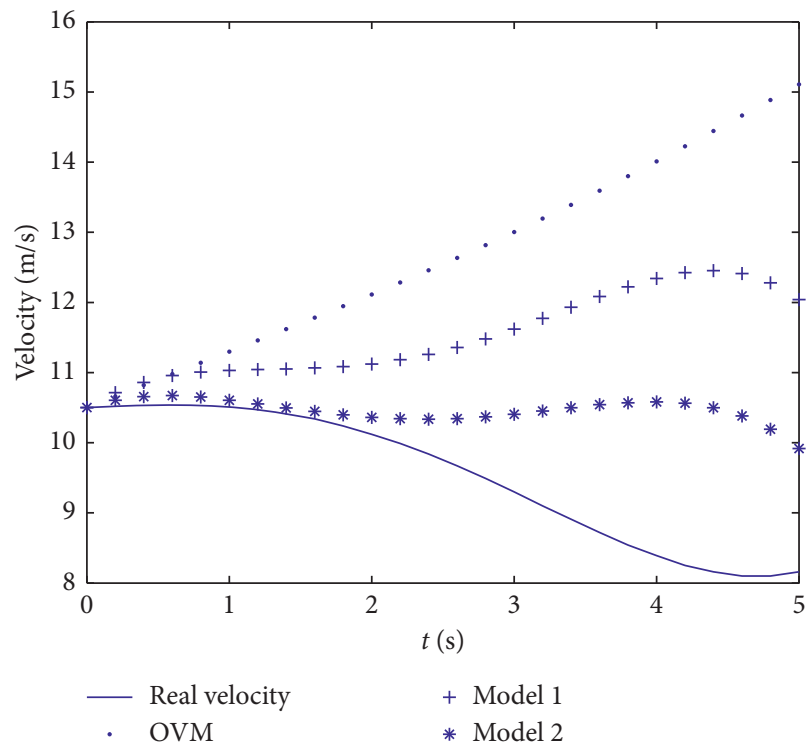

(d)

FIGURE 6: Comparison of simulation result: (a) the first sets of data; (b) the second sets of data; (c) the third sets of data; (d) the fourth sets of data. 
TABLE 8: Comparison of evaluation indexes.

\begin{tabular}{|c|c|c|c|c|c|c|c|c|c|}
\hline & \multicolumn{3}{|c|}{ Mean square deviation } & \multicolumn{3}{|c|}{ Maximum absolute error } & \multicolumn{3}{|c|}{ Minimum absolute error } \\
\hline & OVM & Model 1 & Model 2 & OVM & Model 1 & Model 2 & OVM & Model 1 & Model 2 \\
\hline The $1^{\text {st }}$ sets & 2.6328 & 2.4439 & 1.7159 & 3.1469 & 2.9731 & 1.7604 & 1.6116 & 1.6270 & 1.6094 \\
\hline The $2^{\text {nd }}$ sets & 5.2631 & 4.4345 & 1.6431 & 6.7589 & 6.0942 & 1.8630 & 2.1185 & 1.6717 & 1.3226 \\
\hline The $3^{\text {rd }}$ sets & 2.5156 & 0.8557 & 0.5722 & 3.7024 & 1.1396 & 0.8146 & 0.7803 & 0.1869 & 0.0462 \\
\hline The $4^{\text {th }}$ sets & 3.8783 & 2.6183 & 1.3696 & 6.9491 & 4.5116 & 2.4711 & 0.1439 & 0.2392 & 0.1219 \\
\hline Average value & 3.5713 & 2.5881 & 1.3252 & 5.1393 & 3.6796 & 1.7273 & 1.1636 & 0.9312 & 0.7750 \\
\hline
\end{tabular}



(a)



(c)

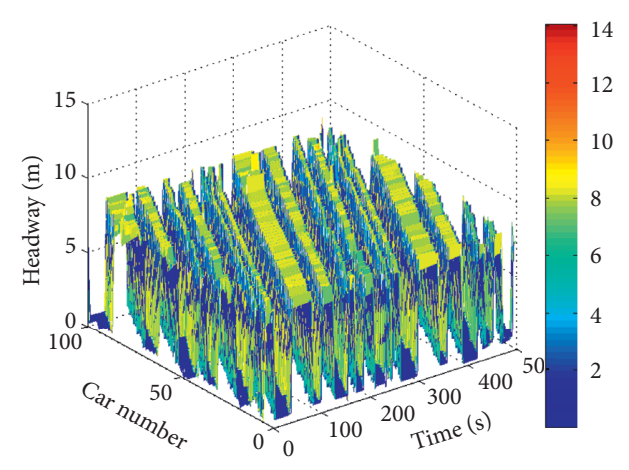

(b)

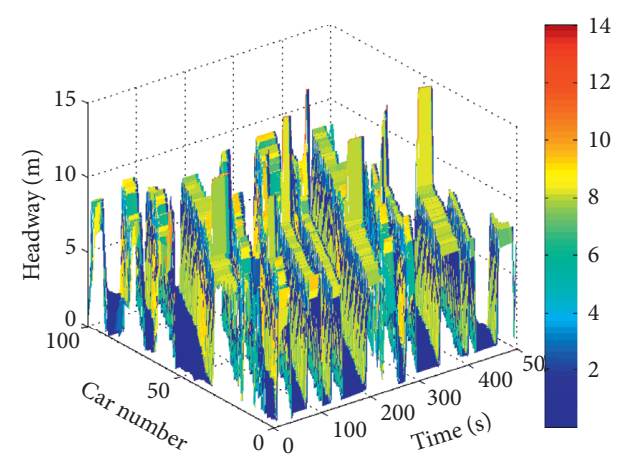

(d)

Figure 7: Space-time evolution of the headway after $t=10000 \mathrm{~s}$ for small disturbance with different $p$ : (a) $p=0$, (b) $p=0.2$, (c) $p=0.4$, and (d) $p=0.6$.

maximum absolute error reduction, and $19.97 \%$ minimum absolute error reduction, respectively. The results indicate that improved model 2 is more suitable than OVM and improved model 1 for describing the traffic phenomena mentioned in this article.

6.2. Density Wave. In order to check the validity of the above theoretical results, we discuss the space-time evolution of the headway for various values of $p$ by using the Euler method in this section. In two adjacent lanes which are named lane 1 and lane 2, all vehicles drive in the same direction with the constant headway $h=4.0 \mathrm{~m}$. Under the periodic boundary condition, the following initial conditions in the two lanes are given as follows:

$$
\Delta x_{1, j}(0)=\Delta x_{1, j}(1)=\cdots=\Delta x_{1, j}(n)=4.0,
$$

$$
\begin{cases}\Delta x_{2, j}(0)=\Delta x_{2, j}(1)=4.0, & \text { for } n \neq 50,51, \\ \Delta x_{2, j}(1)=4.0+0.1, & \text { for } n=50, \\ \Delta x_{2, j}(1)=4.0-0.1, & \text { for } n=51 .\end{cases}
$$

Equations (26) and (27) are, respectively, the initial conditions in lane 1 and lane 2 . The total number of vehicles in each lane is $n=100$. The safety distance is $h_{c}=4.0$. Other input parameters for the simulation are $a=2, v_{\max }=3$. In order to simplify the experiment, we consider the vehicles in lane 2 are in normal driving process; therefore, the driving state of those vehicles can be described by the classic carfollowing model. The vehicles in lane 1 are investigated. Then, space-time evolution of the headway in lane 1 after a sufficiently long time and the corresponding hysteresis loops will be obtained in Figures 7 and 8 . 


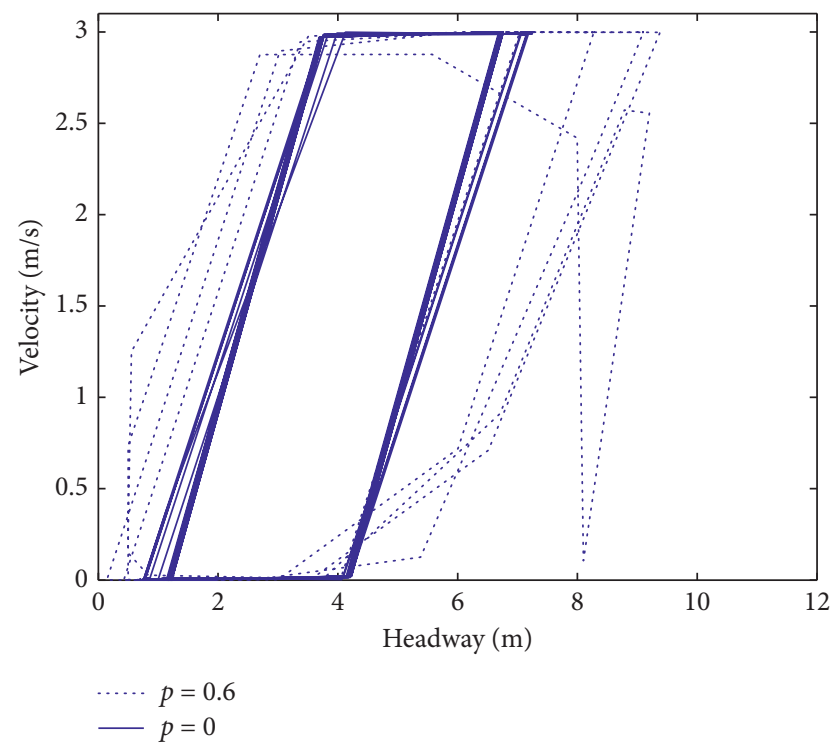

FIGURE 8: Hysteresis loops after $t=10000 \mathrm{~s}$ with different sets of $p$.

Figure 7 shows the space-time evolution of the headway for different sets of $p$ after $t=10000 \mathrm{~s}$. The patterns (a)-(d) are, respectively, corresponding to $p=0,0.2,0.4$, and 0.6 . Muramatsu and Nagatani [26] present the solution of MKDV equation can be exhibited as kink-antikink wave. From Figure 7, because of the lateral influence from the vehicles in lane 2, disturbance generates in the uniform flow in lane 1. Small disturbance added to the uniform traffic flow is amplified, and the kink-antikink wave appears as traffic jam. Only parts of the vehicles in lanel are affected by the lateral vehicle, so the amplitudes of the density wave are not uniform. In addition, it can be seen clearly from Figure 7 that the amplitudes of the density wave increase with increasing $p$. It indicates that the greater the lateral influence, the more unstable the traffic flow is.

Figure 8 exhibits the hysteresis loops after $t=10000 \mathrm{~s}$ with different sets of $p$. The solid line and dotted line are, respectively, obtained with $p=0$ and $p=0.6$. Hysteresis loop has a larger size means that the stability of traffic flow is lower, and the stability of traffic flow is improved with the decrease of the size of the loop. From Figure 8, we can see that the hysteresis loop obtained with $p=0.6$ is much larger than that with $p=0$. The result indicates that by taking lateral influence into account, the stability of the traffic flow decreases, which is in accordance with the linear stability analysis and nonlinear analysis in Sections 4 and 5, respectively.

\section{Conclusion}

In this paper, we describe a kind of traffic phenomenon that the driver often does not keep up with the leading vehicle but drives at a velocity similar to that of the surrounding vehicles. Because of special reasons such as weather condition, health conditions, driving technology, and personal habits, the driver does not always keep up with the leading vehicle but maintains a larger distance from the leading vehicle to leave more reaction time. This phenomenon is an incomplete car-following behavior. With the consideration of the lateral vehicle's influence, we put forward two improved models with different structures on the base of the OV model in this paper. The new improved models are verified by multiple sets of measured data. Linear stability analysis and nonlinear analysis are carried out to study the traffic characteristics. The results of linear stability analysis and numerical simulation show that with increase of lateral influence, traffic flow is more unstable, which is in accordance with the traffic phenomenon that lateral interference can affect driving.

\section{Data Availability}

The real traffic data used to support the findings of this study are included within the article. There are no restrictions on data access.

\section{Conflicts of Interest}

The authors declare that they have no conflicts of interest.

\section{Acknowledgments}

This work was partially supported by the National Nature Science Foundation of China (grant nos. 61134004 and 61863032), China Postdoctoral Science Foundation (grant no. 2018M633653XB), Gansu Province Educational Research Project (grant no. 2015B-130), and “Qizhi” Personnel Training Support Project of Lanzhou Institute of Technology (grant no. 2018QZ-11).

\section{References}

[1] L. A. Pipes, "An operational analysis of traffic dynamics," Journal of Applied Physics, vol. 24, no. 3, pp. 274-281, 1953.

[2] G. F. Newell, "Nonlinear effects in the dynamics of car following," Operations Research, vol. 9, no. 2, pp. 209-229, 1961.

[3] M. Bando, K. Hasebe, A. Nakayama, A. Shibata, and Y. Sugiyama, "Dynamical model of traffic congestion and numerical simulation," Physical Review E, vol. 51, no. 2, pp. 1035-1042, 1995.

[4] D. Helbing and B. Tilch, "Generalized force model of traffic dynamics," Physical Review E, vol. 58, no. 1, pp. 133-138, 1998.

[5] R. Jiang, Q. S. Wu, and Z. J. Zhu, "Full velocity difference model for a car-following theory," Physical Review E, vol. 64, no. 1, pp. 63-66, 2001.

[6] C. Wagner, "Asymptotic solutions for a multi-anticipative car-following model," Physica A: Statistical Mechanics and Its Applications, vol. 260, no. 1-2, pp. 218-224, 1998.

[7] K. Hasebe, A. Nakayama, and Y. Sugiyama, "Equivalence of linear response among extended optimal velocity models," Physical Review E, vol. 69, no. 1, Article ID 017103, 2004.

[8] X. Chen, Z. Y. Gao, and X. M. Zhao, "Study on the two-lane feedback controled car-following model," Acta Physica Sinica, vol. 56, pp. 2024-2029, 2007.

[9] Z. Li, X. Xu, S. Xu, and Y. Qian, "A heterogeneous traffic flow model consisting of two types of vehicles with different sensitivities," Communications in Nonlinear Science and Numerical Simulation, vol. 42, pp. 132-145, 2017. 
[10] G. Peng, S. Yang, D. Xia, and X. Li, "Delayed-feedback control in a car-following model with the combination of V2V communication," Physica A: Statistical Mechanics and Its Applications, vol. 526, Article ID 120912, 2019.

[11] D.-W. Liu, Z.-K. Shi, and W.-H. Ai, "Enhanced stability of car-following model upon incorporation of short-term driving memory," Communications in Nonlinear Science and Numerical Simulation, vol. 47, pp. 139-150, 2016.

[12] T. Q. Tang, H. J. Huang, and Z. Y. Gao, "Stability of the carfollowing model on two lanes," Physical Review E, vol. 72, Article ID 066124, 2005.

[13] T. Tang, H. Huang, S. C. Wong, and R. Jiang, "A car-following model with the anticipation effect of potential lane changing," Acta Mechanica Sinica, vol. 24, no. 4, pp. 399-407, 2008.

[14] H.-x. Ge, X.-p. Meng, H.-b. Zhu, and Z.-P. Li, "Feedback control for car following model based on two-lane traffic flow," Physica A: Statistical Mechanics and Its Applications, vol. 408, no. 15, pp. 28-39, 2014.

[15] Y. Mei, X. Zhao, Y. Qian, S. Xu, Y. Ni, and Z. Li, “Analyses of self-stabilizing control strategy effect in macroscopic traffic model by utilizing historical velocity data," Communications in Nonlinear Science and Numerical Simulation, vol. 74, pp. 55-68, 2019.

[16] T.-Q. Tang, Y.-X. Rui, J. Zhang, and H.-Y. Shang, "A cellular automation model accounting for bicycle's group behavior," Physica A: Statistical Mechanics and Its Applications, vol. 492, pp. 1782-1797, 2018.

[17] J. Tian, G. Li, M. Treiber, N. Jiang, S. Jia, and S. F. Ma, "Cellular automaton model simulating spatiotemporal patterns, phase transitions and concave growth pattern of oscillations in traffic flow," Transportation Research Part B: Methodological, vol. 93, pp. 560-575, 2016.

[18] Z. Li, R. Zhang, S. Xu, and Y. Qian, "Study on the effects of driver's lane-changing aggressiveness on traffic stability from an extended two-lane lattice model," Communications in Nonlinear Science and Numerical Simulation, vol. 24, no. 1-3, pp. 52-63, 2015.

[19] G. Peng, W. Lu, H. He, and Z. Gu, "Nonlinear analysis of a new car-following model accounting for the optimal velocity changes with memory," Communications in Nonlinear Science and Numerical Simulation, vol. 40, pp. 197-205, 2016.

[20] J. Zhang, T.-Q. Tang, and S.-W. Yu, "An improved car-following model accounting for the preceding car's taillight," Physica A: Statistical Mechanics and Its Applications, vol. 492, pp. 1831-1837, 2018.

[21] W.-X. Zhu and H. M. Zhang, "Analysis of mixed traffic flow with human-driving and autonomous cars based on carfollowing model," Physica A: Statistical Mechanics and Its Applications, vol. 496, pp. 274-285, 2018.

[22] P. F. Tao, S. Jin, and D. H. Wang, "Car-following model based on artificial potential field," Journal of Southeast University: Natural Science Edition, vol. 41, no. 4, pp. 854-858, 2011.

[23] M. Mai, L. Wang, and G. Prokop, "Advancement of the car following model of Wiedemann on lower velocity ranges for urban traffic simulation," Transportation Research Part F: Traffic Psychology and Behaviour, vol. 61, pp. 30-37, 2019.

[24] S. Yu, X. Zhao, Z. Xu, and Z. Shi, "An improved car-following model considering the immediately ahead car's velocity difference," Physica A: Statistical Mechanics and Its Applications, vol. 461, pp. 446-455, 2016.

[25] S. Sawada, "Nonlinear analysis of a differential-difference equation with next-nearest-neighbour interaction for traffic flow," Journal of Physics A: Mathematical and General, vol. 34, no. 50, pp. 11253-11259, 2001.
[26] M. Muramatsu and T. Nagatani, "Soliton and kink jams in traffic flow with open boundaries," Physical Review E, vol. 60, no. 1, pp. 180-187, 1999. 